\title{
MRS-Korea Holds Inaugural Ceremonies
}

As interests in new materials and process technologies have increased in Korea, much interdisciplinary effort has been extended to the exchange of information and cooperation between researchers and scientists working in the fields of metals, ceramics, polymers, electricity, electronics, and other areas. To respond to the needs of the times and the demands for collaboration and communication, the Materials Research Society of Korea (MRS-Korea) was founded on February 23 this year.

The inaugural meeting of the Materials Research Society of Korea was held in Seoul, with 135 originating members as well as many other scientists attending. The ceremonies were graced by congratulatory addresses from Korea's Minister of Science and Technology, from Prof. R.P.H. Chang, president of the International Union of Materials Research Societies, and from Prof. S. Sōmiya, president of MRSJapan, who also gave an invited lecture.

Dr. M.C. Chon, president of Chon International Co., Ltd. was elected the first president of MRS-Korea. Four vice presidents were also elected: Prof. J.T. Song of

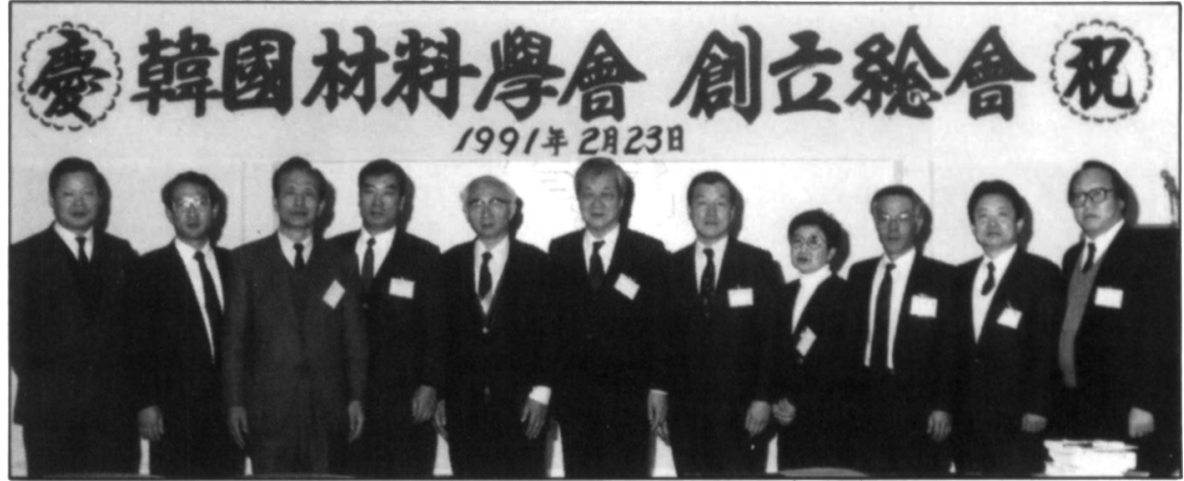

Dr. M.C. Chon (sixth from the left), first president of MRS-Korea, with several of its directors and Prof. S. Somiya (fifth from the left), president of MRS-Japan.

Hanyang University, Prof. S.J. Park of Seoul National University, Prof. K.S. Maeng of Chungnam National University, and Dr. K.H. Oh, managing director at $\mathrm{Hy}-$ undai Electronics Industries Co., Ltd.

MRS-Korea has pledged to promote technological interchange at home and abroad. The Society plans to foster close relationships with MRS members of materials-related societies in other countries through active participation in various technical meetings and conferences.

\section{NEW DIRECTIONS IN MATERIALS RESEARCH}

New!

JOURNAL OF

INORGANIC AND ORGANOMETALLIC POLYMERS

Editor: Martel Zeldin

This international, interdisciplinary publication, appearing quarterly in 1991, publishes peer-reviewed papers and short communications on the synthesis, characterization, evaluation, and various phenomena in inorganic and organometallic polymers; invited review articles on timely topics that deserve a comprehensive overview; and book reviews.

Write to our Sample Copy Dept. for a free examination issue.

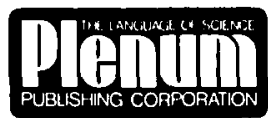

PLENUM PUBLISHING CORPORATION

233 Spring St.. New York. NY 10013 $1-800-221 \cdot 9369 /(212) 620.8000$

\section{FUNDAMENTALS OF ADHESION \\ edited by Lieng-Huang Lee}

Fundamentals of Adhesion provides a comprehensive account of adhesion, with or without the use of an adhesive. Contributors present a broad overview of the new fields of electronic, medical, and biological applications, as they investigate why solids stick together. Chapters address the chemical and electrostatic aspects of bond-forming mechanisms, the effects of molecular forces of bond-forming, and the importance of thermodynamics and kinetics of adhesion, including the roles of wetting and diffusion. In addition, the functions of coupling agents and metal, thin-film, and bio-adhesion are detailed. 0.306-43470-9/472 pp./ill./1991/\$89.50 (\$107.40 outside US \& Canada)

\section{ADHESIVE BONDING} edited by Lieng-Huang Lee

This introductory text provides both theoretical and practical information on the fundamentals of bond-forming and bond-breaking with the aid of polymeric adhesives. A wellcoordinated, practical tool, this volume explains how to determine the durability of adhesive bonds by the analysis of test results. Leading experts discuss the rheological aspects of adhesives and adhesion, the measurements of rheological and dynamical properties of adhesives and sealants, and new methods of characterizing adherends and related interfaces. 0.306-43471-7/496 pp./ill./1991/ $\$ 95.00$ ( $\$ 114.00$ outside US \& Canada) Two-volume set price: $\$ 155.00$ ( $\$ 186.00$ outside US \& Canada) 